\title{
Direct-acting antiviral treatment in real world patients with hepatitis $C$ not associated with psychiatric side effects: a prospective observational study
}

\author{
Isak Sundberg ${ }^{1 *}$ (D), Anders Lannergård ${ }^{2}$, Mia Ramklint ${ }^{1}$ and Janet L. Cunningham ${ }^{1}$
}

\begin{abstract}
Background: Treatment of Hepatitis C virus (HCV) infection has evolved from interferon (IFN)-based treatments to direct-acting antivirals (DAAs). Patients with HCV have an elevated psychiatric morbidity (including substance abuse) and patients with such comorbidity have often been excluded from treatment with IFN. To date, little is known about psychiatric adverse effects of DAA-based regimens. We therefore aimed to study the psychiatric side effects of new IFN-free treatment for HCV (including depressive symptoms and sleep) in real world patients also including those with a history of psychiatric diagnosis, substance abuse or drug dependence.

Methods: Consecutive patients were monitored during treatment with three of the latest DAA agents (sofosbuvir, simeprevir and daclatasvir). Repeated expert psychiatric assessments from baseline to 12 weeks post-treatment were performed with the Structured Clinical Interview for DSM-IV Axis I Disorders (SCID-I) clinical version and the self-report versions of the Montgomery Åsberg Depression Rating Scale (MADRS-S) and the Pittsburgh Sleep Quality Index (PSQI). Friedman's test was performed to calculate differences in the MADRS-S and PSQI over time. In a post-hoc analysis Wilcoxon's test was used to compare baseline depressive symptoms with those at post-treatment. Spearman's rank correlation test was conducted in another post-hoc analysis to evaluate the correlation between symptoms of depression and HCV viral load at baseline.
\end{abstract}

Results: At baseline, 15/17 patients (88\%) had a history of any psychiatric diagnosis; 11 (65\%) had a history of substance abuse or dependence; and 11 (65\%) had previously been treated with IFN and six of those had experienced psychiatric side effects. There was no correlation between depressive symptoms and HCV viral load at baseline. Symptoms of depression did not increase during DAA treatment and were lower 12 weeks post-treatment compared with baseline: MADRS-S 10.7 vs. $8.3(p=0.01$ ). This observation held when excluding patients taking antidepressant medication. Sleep quality did not significantly change during treatment. Adherence to treatment was estimated to $95 \%$ and sustained virological response was $88 \%$.

Conclusions: Despite high psychiatric morbidity, including previous substance abuse, patients successfully completed DAA treatment without increasing depressive symptoms or sleep disturbance. Symptoms of depression were significantly reduced 12 weeks after DAA treatment.

Keywords: Hepatitis C virus, Direct-acting antiviral, Depression, Sleep, Side effects

\footnotetext{
* Correspondence: isak.sundberg@neuro.uu.se

${ }^{1}$ Department of Neuroscience, Psychiatry, Uppsala University Hospital,

Entrance 10, Floor 3B, 75185 Uppsala, Sweden

Full list of author information is available at the end of the article
}

(c) The Author(s). 2018 Open Access This article is distributed under the terms of the Creative Commons Attribution 4.0 International License (http://creativecommons.org/licenses/by/4.0/), which permits unrestricted use, distribution, and reproduction in any medium, provided you give appropriate credit to the original author(s) and the source, provide a link to the Creative Commons license, and indicate if changes were made. The Creative Commons Public Domain Dedication waiver (http://creativecommons.org/publicdomain/zero/1.0/) applies to the data made available in this article, unless otherwise stated. 


\section{Background}

Hepatitis $\mathrm{C}$ virus (HCV) infection is an important cause of chronic liver disease worldwide with an estimated 185 million people infected. Moreover, it is among the leading causes of end-stage hepatic disease and is associated with the development of hepatocellular cancer [1]. Until 2011, the gold standard of care for HCV treatment was the combination of pegylated interferon alpha (PEG-IFN- $\alpha$ ) and ribavirin (RBV), which are nonspecific immune boosters [2, 3]. A major disadvantage of this therapy has been frequent side effects that are largely attributed to IFN- $\alpha$. Psychiatric side effects during IFN- $\alpha$ treatment include depressive symptoms in $30-70 \%$, mild to moderate depression in $45-60 \%$ and major depression in $15-45 \%$ of treated individuals [4]. IFN- $\alpha$ triggers a series of hypothalamic-pituitary-adrenal axis abnormalities and immune responses, resulting in depressive symptoms [5]. Sleep disturbance is common in chronic $\mathrm{HCV}$ infection and treatment with IFN- $\alpha$ confers an additional risk of sleep disturbance of about 20\% [6].

Psychiatric morbidity in patients with $\mathrm{HCV}$ infection is elevated and otherwise eligible patients have frequently not received treatment because of the fear of an exacerbation of psychiatric symptoms [4, 7-9]. A few studies suggest psychiatric comorbidity and drug abuse to be risk factors for non-adherence and not attaining sustained viral response (SVR) [10-12], whereas several other studies have demonstrated similar rates of adherence and SVR in patients with $\mathrm{HCV}$ infection and psychiatric comorbidity (including drug abuse) [13-17]. In a recent study the prevalence of drug use in the past year was $65 \%(201 / 309)$ in patients considering $\mathrm{HCV}$ treatment [18]. In the same material the prevalence of a lifetime psychiatric diagnosis was $88 \%$ and the prevalence of a current psychiatric diagnosis was 54\% [19]. $\mathrm{HCV}$ infection per se may contribute to psychiatric symptoms by inflammatory routes, direct brain neurotoxicity, metabolic and neurotransmitter pathway derangement and immune-mediated responses [20, 21].

The arrival of direct-acting antiviral agents (DAAs) has drastically changed $\mathrm{HCV}$ treatment by increasing the likelihood of cure (referred to as SVR) and shortening the duration of treatment $[22,23]$. The current generation of DAAs (e.g., daclatasvir [DCV], sofosbuvir [SOF], simeprevir [SIM] and ledipasvir [LDV]) is used without IFN $[24,25]$. Because DAAs are not inflammatory cytokines, they should not share the same side effects as IFN- $\alpha$ and RBV of inducing flu-like symptoms, depression or suicidality. The side effect profile of DAAs compared with previous $\mathrm{HCV}$ medications is reported to be less severe [26] and patient-reported outcomes (PROs) improved [27, 28]. Although there are efficacy studies with DAAs that include patients with psychiatric comorbidity, [29, 30], few studies have specifically addressed psychiatric symptoms in DAA treatment $[7,13]$. A recent retrospective study that excluded patients with substance abuse and prior IFN-based treatment found that symptoms of depression decreased after treatment with DAA. This study also reported equal adherence and SVR rates in patients with indications of mental disease compared with those without [31]. More data are needed to assess PROs and treatment adherence of patients with $\mathrm{HCV}$ in clinical practice [22, 28, 32].

Against this background, it is essential to study side effects, adherence and efficacy in a real-world patient population, where psychiatric comorbidity (including substance abuse) is common. Therefore, this study seeks to identify psychiatric side effects in $\mathrm{HCV}$ patients receiving DAAs (DCV, SOF and SIM), with repeated observations from baseline to 12 weeks post-treatment. To our knowledge, this is the first study to specifically monitor psychiatric side effects in DAA treatment in real-world patients with psychiatric morbidity including past substance abuse.

\section{Methods \\ Subjects}

This study was initiated in 2013, shortly before new DAA treatments were introduced, with the aim to study the longitudinal relationship between psychiatric symptoms and HCV treatment. Patients were recruited from a group of patients treated by a specialist in infectious disease (AL) at the Department of Infectious Diseases, Uppsala University Hospital. The eligible patients for DAA treatment were those without malignancy. Patients with advanced liver fibrosis and cirrhosis, extrahepatic diseases, as well as those with strong psychosocial reasons for treatment were prioritised for inclusion.

Exclusion criteria were inability to read or write Swedish and low cognitive or intellectual ability. These criteria were considered incompatible with completing an extensive research protocol and undergoing an in-depth inquiry with recurrent interviews. Sixty-three consecutive patients were considered for participation in this study between June 2014 and April 2015. Eleven were excluded because of a lack of Swedish language skills or low cognitive or intellectual functioning. This selection was made by the treating specialist (AL) at the Department of Infectious Diseases, Uppsala University Hospital, based on clinical judgement of the patient's ability to understand and complete the study protocol with repeated assessments in the Swedish language. Of the 52 eligible patients, 19 (37\%) accepted and were included in the study. Two of those patients declined to start the study before the first visit. Thus, the final sample was composed of $17 / 52$ patients (33\%). The patients represented the spectrum of individuals considered suitable for treatment of HCV. None of the patients had HBV-HCV 
or HIV-HCV co-infection. A flow chart of the patient inclusion process is provided in Fig. 1.

\section{Design}

The study was a prospective observational study. The choice of treatment regimen was based on actual Swedish national recommendations by The Swedish Medical Products Agency at the time of treatment [33]. The prescription was combined with a treatment schedule that was carefully supervised by research nurses at the outpatient ward. Before treatment start, the physician reviewed laboratory data, liver elasticity, biopsy data and concomitant medication. A visit was scheduled every four weeks during treatment. After the treatment was completed, follow-up visits were performed at 12 and 24 weeks. At each time point, research nurses asked the participants about adherence to medication (taking DAA medication as prescribed or not), which was then noted in the medical records. Psychiatric assessment and patient self-report measures were employed at baseline, after 4 weeks of treatment, after 8 weeks of treatment, at the end of treatment and 12 weeks post-treatment.

Information was gathered on sociodemographic data, medical history and treatment from the patients and medical records. Patients and providers were blinded to the HCV RNA results at the time of completion of the questionnaires, but not blinded to the HCV RNA results from earlier time points in the study.

\section{Psychiatric assessment}

At baseline, patients were assessed for past and current psychiatric morbidity by a trained psychiatrist (IS) using the Structured Clinical Interview for DSM-IV Axis I Disorders (SCID-I) clinical version. Previous HCV treatment and psychiatric side effects were also addressed in the interview. In following visits (including the 12-week post-treatment visit), patients were interviewed by the principal author, using module A of the SCID-I to assess the presence of depressive episodes according to DSM-IV.

\section{Self-assessment}

Symptoms of depression were measured using the self-rating version of the Montgomery Åsberg Depression Rating Scale (MADRS-S). It has been shown to be a reliable and sensitive self-report tool for depressive symptoms [34] and thus suitable to follow patients with depressive symptoms over time. Scores on the MADRS-S range from 0 to 54, with higher scores indicating a greater severity of depression [35]. Sleep quality

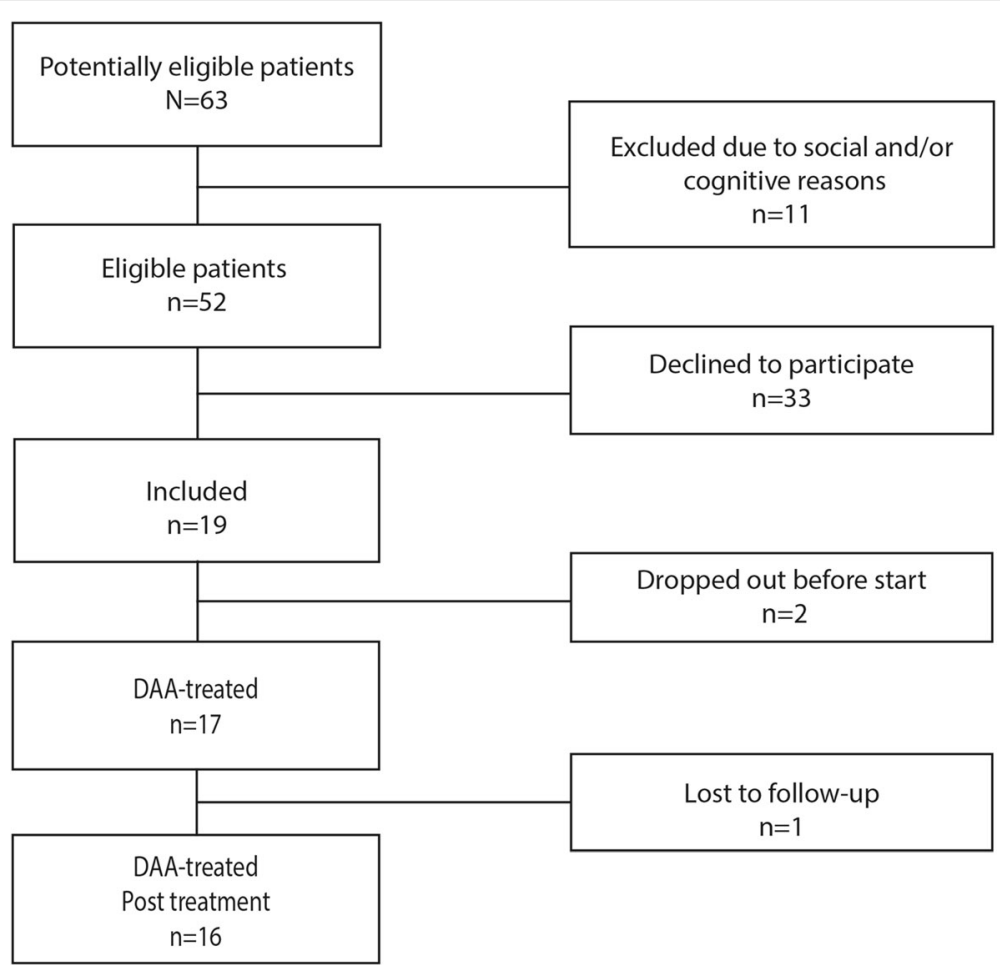

Fig. 1 Patient inclusion. Sixty-three consecutive patients were considered for this study. Eleven were excluded because they could not speak or write fluently in Swedish or had low cognitive/intellectual ability. Of the 52 eligible patients, 19 accepted and were included in the study. Two patients declined to participate before study start. One patient was diagnosed with lung cancer and had to discontinue treatment at week 11. Sixteen of 17 patients completed the study 
was measured with the Pittsburgh Sleep Quality Index (PSQI), a validated self-rated questionnaire assessing sleep quality and disturbances over a one month period [36]. The PSQI measures several aspects of sleep (e.g., sleep latency, sleep duration, habitual sleep efficiency and sleep disturbances). This tool includes seven component scores (range 0-3), as well as a composite global score (range 0-21). At each visit, patients filled in the MADRS-S and PSQI questionnaires. To screen for alcohol and drug use, the Alcohol Use Disorders Identification Test (AUDIT) [37] and Drug Use Disorders Identification Test (DUDIT) [38] were completed at baseline, after 12 weeks of treatment and 12 weeks post-treatment. The AUDIT is a 10-item screening instrument to assess alcohol consumption, drinking behavior and problems related to alcohol consumption. The DUDIT serves as a parallel tool to the AUDIT to identify persons with drug-related problems.

\section{Laboratory tests}

HCV RNA was obtained from blood samples and analysed at each time point. All analyses were conducted at the Department of Clinical Chemistry at Uppsala University Hospital. A negative test for HCV RNA (detection limit of ' $15 \mathrm{IU} / \mathrm{mL}$ ) at both 12 and 24 weeks post-treatment was considered as a SVR. The rate of the SVR was calculated on an "intention to treat" basis - i.e. all the patients who started treatment.

\section{Statistics}

Non-parametric tests were used to calculate differences in MADRS-S, PSQI, AUDIT and DUDIT over time (Friedman's test) and between depressive symptoms and HCV viral load at baseline (Spearman's rank correlation test). In a post-hoc analysis Wilcoxon's test was applied to compare baseline depressive symptoms with post-treatment depressive symptoms. All statistical analyses were conducted with the Statistical Package for the Social Sciences version 2 (SPSS Inc., Chicago, IL, USA). Reported $p$-values are two-sided with statistical significance set at $p<0.05$.

\section{Results}

Patient characteristics are presented in Table 1. All DAA-treated patients (17/17) received treatment with SOF combined with either SIM 9/17 (53\%), DCV 7/17 (41\%) or LDV $1 / 17$ (6\%). Additionally, 2/17 (12\%) patients received RBV.

\section{Treatment adherence and response}

At $95 \%$ of the visits, patients reported taking their DAA medication as prescribed. Fifteen of 17 (88\%) patients reached SVR at both 12 and 24 weeks. One male patient had a virological relapse. A female patient was diagnosed with lung cancer during the treatment; this individual had a negative HCV test $(<15 \mathrm{IU} / \mathrm{mL})$ at 4 and 8 weeks of treatment and discontinued treatment at week 11 .

One patient attained SVR but developed hepatocellular cancer shortly after completing DAA treatment. Ultrasound of the liver and computer tomography of the upper abdomen was performed before DAA treatment for this patient showing no indication of malignancy.

\section{Psychiatric morbidity at baseline}

According to the SCID-I, 15/17 patients (88\%) had any lifetime DSM IV psychiatric diagnosis. At baseline, 6/17 patients (35\%) had an ongoing DSM IV psychiatric diagnosis. The number of lifetime psychiatric diagnoses ranged from 0 to 7 (median 2). Eleven of 17 patients (65\%) had previous abuse or dependence of drugs or alcohol. Eleven of 17 patients (65\%) were previously treated with IFN for HCV but the treatment had not been successful because of relapse $(n=3)$, intolerance $(n=3)$, partial response $(n=3)$ and viral breakthrough $(n=2)$. Retrospectively, at least two of the previously treated patients had developed a depressive episode during treatment (according to the psychiatric assessment with SCID-I) while another four had developed depressive symptoms. One patient had developed diabetes, which is a reported side effect of IFN/RBV treatment [39-41].

\section{Relationship between depressive symptoms and HCV viral load at baseline}

There was no significant correlation between baseline symptoms of depression and HCV viral load at baseline (Spearman's rho: $r=0.17, p=0.55$ ).

\section{Depressive symptoms during DAA treatment}

MADRS-S scores for each visit were available for $15 / 17$ patients (one patient was lost to follow-up because of lung cancer and one missed filling in the MADRS-S at one of the assessment visits). For these 15 remaining patients, the mean MADRS-S score was 10.7 (range 1-30, $S D$ 7.9) at baseline, 7.2 (range 0-26, $S D$ 7.1) after 4 weeks, 7.3 (range 0-19, SD 5.7) after 8 weeks, 8.0 (range $0-25, S D 7.4$ ) at the end of treatment and 8.3 (range $0-30, S D$ 8.3) at 12 weeks post-treatment (Fig. 2).

No statistical difference in MADRS-S levels was found when comparing all test points (Friedman test $X^{2}=4.03$, $p=0.40$ ), indicating that depressive symptoms did not increase during treatment. We observed a significant difference when comparing baseline MADRS-S with 12 -week post-treatment (Wilcoxon $p=0.01$ ), i.e. there were less depressive symptoms post-treatment.

Reanalysis, omitting those three patients taking antidepressant medication again found no statistical difference in MADRS-S levels when comparing all test points (Friedman test $X^{2}=4.6, p=0.33$ ) and a 
Table 1 Baseline characteristics and psychiatric morbidity

\begin{tabular}{|c|c|c|}
\hline Age, mean (range) & 58 & $(44-67)$ \\
\hline Male sex, n (\%) & 9 & (53) \\
\hline BMI, mean (range) & 27.2 & $(17.5-35.6)$ \\
\hline HCV RNA IE/mL, median (range) & $2.6 \times 10^{6}$ & $\begin{array}{l}\left(2.8 \times 10^{5}-\right. \\
\left.16 \times 10^{6}\right)\end{array}$ \\
\hline \multicolumn{3}{|l|}{ HCV genotype, n (\%) } \\
\hline $1 \mathrm{a}$ & 7 & $(41)$ \\
\hline $1 b$ & 3 & (18) \\
\hline $3 a$ & 5 & (29) \\
\hline $1 \mathrm{a} / 1 \mathrm{~b} / 1 \times$ & 2 & $(12)$ \\
\hline \multicolumn{3}{|l|}{ Descent } \\
\hline European & 16 & $(94)$ \\
\hline Middle Eastern & 1 & $(6)$ \\
\hline Previous IFN treatment, n (\%) & 11 & $(65)$ \\
\hline Psychiatric side effects during IFN treatment, $\mathrm{n}$ & 6 & \\
\hline Liver cirrhosis, n (\%) & 10 & $(59)$ \\
\hline Child-Pugh A & 9 & \\
\hline Child-Pugh B & 1 & \\
\hline Current psychiatric morbidity, n (\%) & 6 & $(35)$ \\
\hline Any mood disorder & 4 & $(24)$ \\
\hline Any substance abuse or dependence ${ }^{a}$ & 2 & $(12)$ \\
\hline Any anxiety disorder & 1 & (6) \\
\hline $\mathrm{ADHD}^{\mathrm{C}}$ & 2 & $(12)$ \\
\hline Lifetime psychiatric morbidity, n (\%) & 15 & $(88)$ \\
\hline Any mood disorder & 10 & (59) \\
\hline Any psychotic disorder ${ }^{b}$ & 1 & (6) \\
\hline Any substance abuse or dependence & 11 & $(65)$ \\
\hline Any anxiety disorder & 6 & (35) \\
\hline Any eating disorder & 2 & $(12)$ \\
\hline $\mathrm{ADHD}^{c}$ & 2 & $(12)$ \\
\hline \multicolumn{3}{|l|}{ Psychotropic medication } \\
\hline Any psychotropic medication & 8 & $(47)$ \\
\hline Antidepressants & 3 & $(18)$ \\
\hline Benzodiazepines & 3 & $(18)$ \\
\hline Benzodiazepine-like agents for sleep & 3 & (18) \\
\hline Central nervous system stimulants & 1 & (6) \\
\hline Buprenorphine & 2 & $(12)$ \\
\hline
\end{tabular}

a Patients were in an opiate substitution treatment programme

${ }^{\mathrm{b}}$ Substance-induced psychotic disorder

c $A D H D$, attention-deficit/hyperactivity disorder based on patient diagnosis in medical records

significant difference was still seen when comparing baseline MADRS-S with 12 weeks after treatment (Wilcoxon $p=0.02$ ).

In one patient adjunctive RBV treatment was discontinued after four weeks because of affected blood count (from 146 to $115 \mathrm{~g} / \mathrm{L}$ ). For this patient, the
MADRS-S score increased from 8 at baseline to 15 after four weeks and then decreased to 11,9 and 8 during the rest of the study.

Three patients were depressed at baseline (based on the psychiatric assessment with the SCID-I). Two patients developed depression during DAA treatment. Of the two patients who developed depression, one described a subthreshold depressive episode at baseline (days with depressed mood but not during two weeks) and the other experienced family psychosocial problems during the treatment period. The latter patient also had a history of recurrent depressive episodes. One patient was depressed 12 weeks after treatment concluded.

\section{Sleep quality during DAA treatment}

Mean total PSQI scores were 7.7 (range 2-19, SD 4.8) at baseline, 7.6 (range 2-18, $S D$ 4.7) after 4 weeks, 7.7 (range 2-19, SD 4.9) after 8 weeks, 7.2 (range 2-19, SD 4.7 ) at the end of treatment and 7.6 (range $3-18, S D$ 4.9) 12 weeks after treatment ended (Fig. 2). No significant variation in total PSQI was noted $\left(X^{2}=3.4, p=0.49\right)$. For PSQI component scores, post-hoc analysis of these measures revealed no significant variation during DAA treatment for sleep duration $\left(X^{2}=2.4, p=0.66\right)$, sleep disturbances $\left(X^{2}=1.8, p=0.77\right)$, sleep latency $\left(X^{2}=2.7\right.$, $p=0.61)$, day dysfunction $\left(X^{2}=5.5, p=0.24\right)$, habitual sleep efficiency $\left(X^{2}=2.4, p=0.67\right)$, and overall sleep quality $\left(X^{2}=3.4, p=0.50\right)$ (Fig. 3).

\section{AUDIT during DAA treatment}

Mean AUDIT scores were 1.9 (range 0-7, SD 2.2) at baseline, 1.5 (range 0-12, SD 3.0) 12 weeks of treatment and 1.9 (range $0-9, \quad S D \quad 2.5$ ) 12 weeks post-treatment. There was no significant variation during treatment $\left(X^{2}=1.15, p=0.59\right)$.

\section{DUDIT during DAA treatment}

Mean DUDIT scores were 2.8 (range $0-41, S D$ 10.0) at baseline, 2.3 (range 0-28, $S D$ 7.0) after 12 weeks of treatment and 0.6 (range $0-7, S D 2.0) 12$ weeks after treatment. One person with previous methamphetamine abuse was taken into a substance abuse treatment centre just before start of the study (and start of treatment). This patient's DUDIT scores were 41 at baseline, 28 after 12 weeks of treatment and 712 weeks post-treatment. She did not report drug abuse during the study, but because the questions in DUDIT refer to "during the last year", high scores can be obtained without ongoing abuse. One patient had slightly increasing DUDİT scores ( 0 at baseline, 4 after 12 weeks of treatment and 7 at 12 weeks post-treatment). No significant variation was found during the treatment $\left(X^{2}=1.2, p=0.55\right)$. 


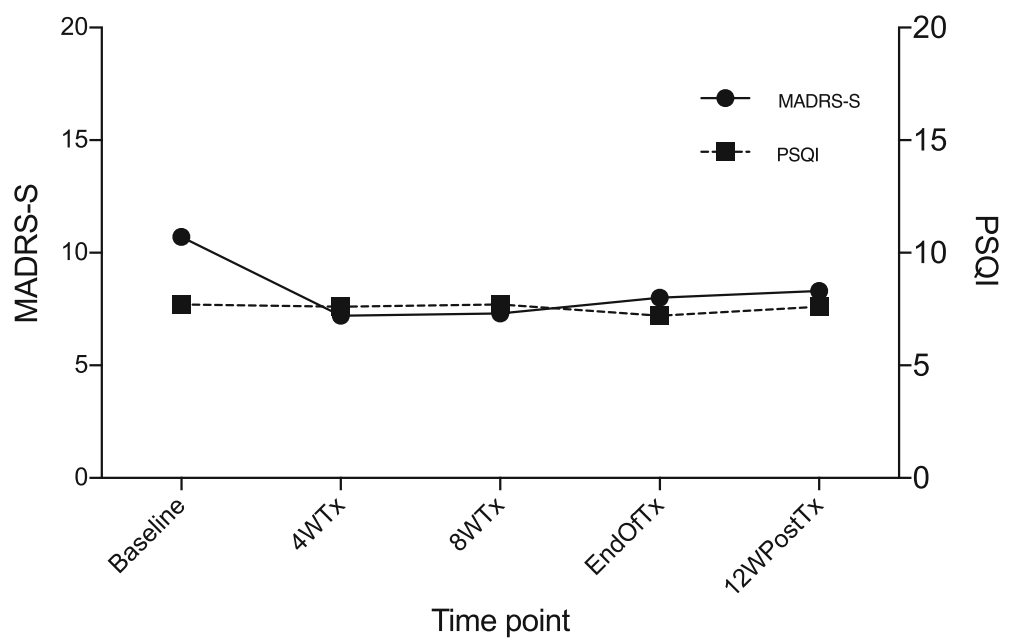

Fig. 2 Mean scores for depressive symptoms (MADRS-S) and sleep quality (Total PSQI) from baseline to post-treatment. Depressive symptoms were lower 12 weeks post-treatment. Total PSQI did not significantly change during DAA treatment. Abbreviations: MADRS-S, self-rating version of the Montgomery Åsberg Depression Rating Scale; PSQI, Pittsburgh Sleep Quality Index; 4WTx, 4 weeks of treatment; 8WTx, 8 weeks of treatment; EOT, end of treatment; 12WpostTx, twelve weeks post-treatment

\section{Discussion}

To our knowledge, this prospective study is the first to specifically examine psychiatric symptoms during DAA treatment in real-world patients with substantial psychiatric morbidity (including a history of substance abuse). In this small but clinically relevant population of $\mathrm{HCV}$ patients with significant psychiatric comorbidity DAA treatment did not increase depressive symptoms or influence sleep quality. In line with previous results adherence in this group was high $(>95 \%)$ as was treatment response (88\%) [26].

In this study, the MADRS-S score was significantly lower 12 weeks after the conclusion of treatment compared with baseline. This finding is in agreement with research showing that mental health parameters, neurocognitive function and fatigue are significantly improved [42-44]. Moreover, a reduction in Beck Depression Inventory scores was seen after

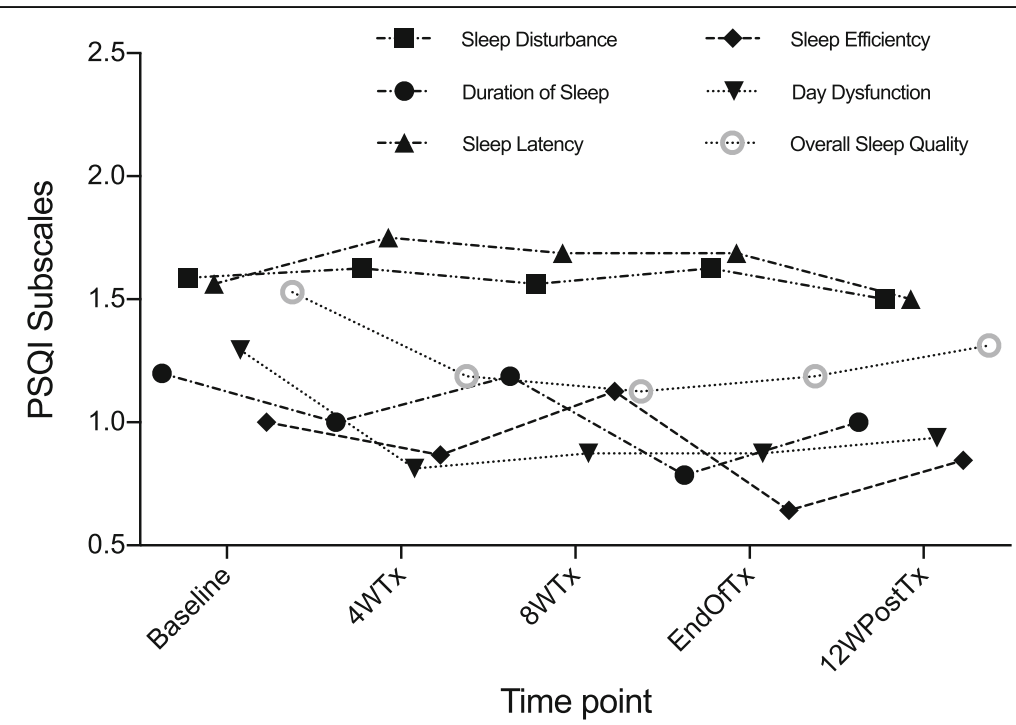

Fig. 3 Mean component scores of the PSQI from baseline to post-treatment. There was no significant change in the component scores of the PSQI during DAA treatment. Abbreviations: PSQI, Pittsburgh Sleep Quality Index; 4WTx, four weeks of treatment; 8WTx, eight weeks of treatment; EOT, end of treatment; 12WpostTx, twelve weeks post-treatment 
treatment with SOF [31]. In addition to the psychological aspect of wellbeing in the virus-free patient [45], pretreatment viral load may contribute directly to inflammation in the central nervous system $[20,21,45,46]$ and to depressive symptoms. The eradication of $\mathrm{HCV}$ with anti-viral treatment may lower inflammation levels, resulting in less psychiatric symptoms [46-48]. In our sample, however, there was no correlation at baseline between viral load and depressive symptoms.

Two patients, who received RBV in addition to DAA, reported increased depressive symptoms during treatment (4-7-point increase in the MADRS-S score). There is no clear evidence linking RBV treatment to depressive symptoms [4]. However, previous studies have mainly focused on IFN- $\alpha$. The depressive effects of IFN- $\alpha$ might have overshadowed smaller psychiatric side effects of RBV.

One strength of this study is its well-characterised patient sample. Another strength is that patients were assessed with gold standard psychiatric evaluation and followed prospectively for 9-12 months with repeated assessments, self-reported measures and clinical, biochemical and virological monitoring. The sample also reflects real world patients, which increases the generalisability of the findings. In contrast to many studies, our study includes patients with a history of substance abuse and IFN-based treatment.

One major limitation of this study is its small sample size. The relatively low inclusion rate was in part due to other ongoing studies at the clinic and may have produced a differential selection effect. A second limitation is that the assessment of language skills and cognitive functioning was based on subjective clinical judgement and was not operationalised formally. The results, such as the high adherence in this study, may therefore not be generalisable to populations with poor language skills and lower cognitive functioning. Yet, the study patients represent a selection of chronic HCV patients regarding psychiatric comorbidity and liver disease typical for our practice and with similar rates of psychiatric comorbidity as in other studies characterising psychiatric comorbidity in chronic HCV patients [18]. Patients' use of psychotropic medication including antidepressants may have mitigated symptoms of depression and thus influenced outcome. This possibility is reflective of a real-life setting, however.

There is evidence that patients with intravenous substance abuse may be at a higher risk of reinfection, but that this risk can be lowered by properly addressing this comorbidity during and after $\mathrm{HCV}$ cure [49-51]. A coherent and comprehensive approach to deal with mental health and substance abuse is likely important to prevent reinfection of $\mathrm{HCV}$.

\section{Conclusions}

Although a majority of patients in this study had a history of affective disorder, drug abuse or neuropsychiatric disorder and previous IFN-based treatment, they were able to complete DAA treatment without substantial psychiatric side effects. Depressive symptoms were reduced after DAA treatment. Our study confirms findings showing that $\mathrm{HCV}$ patients with psychiatric comorbidity can be treated with DAAs with good efficacy and without psychiatric side effects, which is an important finding for $\mathrm{HCV}$ patients previously excluded from $\mathrm{HCV}$ treatment. Further studies with larger patient samples are needed to add strength to these findings.

\section{Abbreviations}

AUDIT: Alcohol Use Disorders Identification Test; DAA: Direct-acting antiviral; DCV: daclatasvir; DUDIT: Drug Use Disorders Identification Test:

HCV: Hepatitis C virus; IFN-a: Interferon alpha; IU/mL: International units per milliliter; MADRS-S: The self-rating version of the Montgomery Åsberg Depression Rating Scale; PSQI: Pittsburgh Sleep Quality Index; RBV: Ribavirin; SIM: Simeprevir; SOF: Sofosbuvir

\section{Acknowledgements}

The authors thank all patients for their participation, the staff at the open ward at the Department of Infectious Diseases, Uppsala University Hospital who collected the data, Hans Arinell for excellent assistance in the statistical analysis and Lisa Ekselius for fruitful discussions concerning study design and data analysis. Sample management has been in collaboration with Uppsala Biobank.

\section{Funding}

This work was funded by Medical Training and Research Agreement (ALF) Funds from Uppsala University Hospital, the Märta och Nicke Nasvells fund, the Erik, Karin and Gösta Selanders Stiftelse, the Fredrik and Ingrid Thurings Stiftelse and The Swedish Society of Medicine. The funders had no role in study design, data collection and analysis, decision to publish, or preparation of the manuscript.

\section{Availability of data and materials}

The datasets used or analysed during the current study are available from the corresponding author on reasonable request.

\section{Authors' contributions}

IS, AL, MR and JC designed the study; IS and AL contributed to data acquisition; IS, AL, MR and JC analysed the data; IS wrote the first draft; AL, $\mathrm{MR}$ and $\mathrm{JC}$ revised and approved the final version of the article. All authors read and approved the final manuscript.

Ethics approval and consent to participate

The study was approved by the Regional Ethics Committee in Uppsala (Dnr. 2013/219). All patients received oral and written information and signed a written consent.

\section{Competing interests}

The authors declare that they have no competing interests.

\section{Publisher's Note}

Springer Nature remains neutral with regard to jurisdictional claims in published maps and institutional affiliations.

\section{Author details}

'Department of Neuroscience, Psychiatry, Uppsala University Hospital, Entrance 10, Floor 3B, 75185 Uppsala, Sweden. ${ }^{2}$ Department of Medical Sciences, Section of Infectious Diseases, Uppsala University Hospital, Entrance 34, Floor 2, 75185 Uppsala, Sweden. 


\section{Received: 26 September 2017 Accepted: 11 May 2018 Published online: 29 May 2018}

\section{References}

1. Saeed Sadiq Hamid, et al. Guidelines for the screening care and treatment of persons with chronic hepatitis $C$ infection: updated version. Geneva: WHO Press; 2016.

2. European Association for the Study of the L. EASL clinical practice guidelines: management of hepatitis C virus infection. J Hepatol. 2011;55(2):245-64.

3. Rehermann B, Bertoletti A. Immunological aspects of antiviral therapy of chronic hepatitis B virus and hepatitis C virus infections. Hepatology. 2015; 61(2):712-21.

4. Schaefer M, Capuron L, Friebe A, Diez-Quevedo C, Robaeys G, Neri S, et al. Hepatitis $C$ infection, antiviral treatment and mental health: a European expert consensus statement. J Hepatol. 2012:57(6):1379-90.

5. Hoyo-Becerra C, Schlaak JF, Hermann DM. Insights from interferon-alpharelated depression for the pathogenesis of depression associated with inflammation. Brain Behav Immun. 2014:42:222-31.

6. Sockalingam S, Abbey SE, Alosaimi F, Novak M. A review of sleep disturbance in hepatitis C. J Clin Gastroenterol. 2010;44(1):38-45.

7. Rowan PJ. What psychiatric screening and monitoring might be needed with the new generation of hepatitis C treatments? World J Virol. 2015:4(1):13-6.

8. Carta MG, Hardoy MC, Garofalo A, Pisano E, Nonnoi V, Intilla G, et al. Association of chronic hepatitis $C$ with major depressive disorders: irrespective of interferon-alpha therapy. Clin Pract Epidemiol Ment Health. 2007;3:22.

9. el-Serag HB, Kunik M, Richardson P, Rabeneck L. Psychiatric disorders among veterans with hepatitis C infection. Gastroenterology. 2002; 123(2):476-82.

10. Niederau C, Mauss S, Schober A, Stoehr A, Zimmermann T, Waizmann M, et al. Predictive factors for sustained virological response after treatment with pegylated interferon alpha-2a and ribavirin in patients infected with HCV genotypes 2 and 3. PLoS One. 2014;9(9):e107592.

11. Younossi Z, Henry L. Systematic review: patient-reported outcomes in chronic hepatitis C-the impact of liver disease and new treatment regimens. Aliment Pharmacol Ther. 2015:41(6):497-520.

12. Mathes $T$, Antoine $S L$, Pieper D. Factors influencing adherence in hepatitis-C infected patients: a systematic review. BMC Infect Dis. 2014;14:203.

13. Sockalingam S, Sheehan K, Feld JJ, Shah H. Psychiatric care during hepatitis $\mathrm{C}$ treatment: the changing role of psychiatrists in the era of direct-acting antivirals. Am J Psychiatry. 2015;172(6):512-6.

14. Elsherif O, Bannan C, Keating S, McKiernan S, Bergin C, Norris S. Outcomes from a large 10 year hepatitis $C$ treatment programme in people who inject drugs: no effect of recent or former injecting drug use on treatment adherence or therapeutic response. PLoS One. 2017:12(6):e0178398.

15. Hauser P, Morasco BJ, Linke A, Bjornson D, Ruimy S, Matthews A, Rifai A, Indest DW, Loftis JM. Antiviral completion rates and sustained viral response in hepatitis $C$ patients with and without preexisting major depressive disorder. Psychosomatics. 2009;50(5):500-5.

16. Schäfer A, Scheurlen M, Weissbrich B, Schöttker $K$, Kraus MR. Sustained virological response in the antiviral therapy of chronic hepatitis $C$ : is there a predictive value of interferon-induced depression? Chemotherapy. 2007; 53(4):292-9

17. Dieperink $E$, Ho SB, Thuras $P$, Willenbring ML. A prospective study of neuropsychiatric symptoms associated with interferon-alpha- $2 b$ and ribavirin therapy for patients with chronic hepatitis C. Psychosomatics. 2003; 44(2):104-12.

18. Sims OT, Pollio DE, Hong BA, Jain MK, Brown GR, North CS. An assessment of concurrent drug and alcohol use among patients seeking treatment for hepatitis C. Ann Clin Psychiatry. 2016;28(1):31-6.

19. North CS, Sims O, Hong BA, Jain MK, Brown G, Lisker-Melman M, Pollio DE. An empirical study of alcohol consumption by patients considering HCV treatment. Am J Drug Alcohol Abuse. 2014;40(6):484-9.

20. Tully DC, Hjerrild S, Leutscher PD, Renvillard SG, Ogilvie CB, Bean DJ, et al. Deep sequencing of hepatitis $C$ virus reveals genetic compartmentalization in cerebrospinal fluid from cognitively impaired patients. Liver Int. 2016;

21. Forton DM, Allsop JM, Main J, Foster GR, Thomas HC, Taylor-Robinson SD. Evidence for a cerebral effect of the hepatitis C virus. Lancet. 2001; 358(9275):38-9.

22. Banerjee D, Reddy KR. Review article: safety and tolerability of direct-acting anti-viral agents in the new era of hepatitis $C$ therapy. Aliment Pharmacol Ther. 2016;43(6):674-96.
23. Gutierrez JA, Lawitz EJ, Poordad F. Interferon-free, direct-acting antiviral therapy for chronic hepatitis C. J Viral Hepat. 2015;22(11):861-70.

24. Coppola N, Zampino R, Bellini G, Stanzione M, Capoluongo N, Marrone A, et al. The impact of the CB2-63 polymorphism on the histological presentation of chronic hepatitis B. Clin Microbiol Infect. 2015;21(6):609 e601-4.

25. Lawitz E, Sulkowski MS, Ghalib R, Rodriguez-Torres M, Younossi ZM, Corregidor A, et al. Simeprevir plus sofosbuvir, with or without ribavirin, to treat chronic infection with hepatitis C virus genotype 1 in non-responders to pegylated interferon and ribavirin and treatment-naive patients: the COSMOS randomised study. Lancet. 2014;384(9956):1756-65.

26. Sulkowski MS, Vargas HE, Di Bisceglie AM, Kuo A, Reddy KR, Lim JK, et al. Effectiveness of Simeprevir plus Sofosbuvir, with or without ribavirin, in realworld patients with HCV genotype 1 infection. Gastroenterology. 2016; 150(2):419-29.

27. Younossi ZM, Stepanova M, Marcellin P, Afdhal N, Kowdley KV, Zeuzem S, Hunt SL. Treatment with ledipasvir and sofosbuvir improves patientreported outcomes: results from the $10 \mathrm{~N}-1,-2$, and -3 clinical trials. Hepatology. 2015;61(6):1798-808

28. Younossi ZM, Stepanova M, Jacobson IM, Asselah T, Gane EJ, Lawitz E, et al. Sofosbuvir and velpatasvir with or without voxilaprevir in direct-acting antiviral-naive chronic hepatitis C: patient-reported outcomes from POLARIS 2 and 3. Aliment Pharmacol Ther. 2018;47(2):259-67.

29. Ho SB, Monto A, Peyton A, Kaplan DE, Byrne S, Moon S, et al. Efficacy of Sofosbuvir plus ribavirin in veterans with hepatitis $C$ virus genotype 2 infection, compensated cirrhosis. and Multiple Comorbidities Clin Gastroenterol Hepatol. 2016;

30. Ioannou GN, Beste LA, Chang MF, Green PK, Lowy E, Tsui Jl, Su F, Berry K. Effectiveness of Sofosbuvir, Ledipasvir/Sofosbuvir, or Paritaprevir/ritonavir/ Ombitasvir and Dasabuvir regimens for treatment of patients with hepatitis $\mathrm{C}$ in the veterans affairs National Health Care System. Gastroenterology. 2016;151(3):457-71. e455

31. Tang LSY, Masur J, Sims Z, Nelson A, Osinusi A, Kohli A, Kattakuzhy S, Polis $M$, Kottilil S. Safe and effective sofosbuvir-based therapy in patients with mental health disease on hepatitis C virus treatment. World J Hepatol. 2016; 8(31):1318-26

32. Jafri SM, Gordon SC. The safety of daclatasvir for the treatment of hepatitis C. Expert Opin Drug Saf. 2015;14(11):1787-97.

33. Läkemedelsbehandling av hepatit C- virusinfektion hos vuxna och barn.kunskapsunderlag [http://docplayer.se/6964210-Lakemedelsbehandling-avhepatit-c-virusinfektion-hos-vuxna-och-barn-kunskapsunderlag.html].

34. Fantino B, Moore N. The self-reported Montgomery-Åsberg depression rating scale is a useful evaluative tool in major depressive disorder. BMC Psychiatry. 2009;9:26.

35. Cunningham $J \mathrm{~L}$, Wernroth $\mathrm{L}$, von Knorring $\mathrm{L}$, Berglund $\mathrm{L}$, Ekselius $\mathrm{L}$. Agreement between physicians' and patients' ratings on the MontgomeryÅsberg depression rating scale. J Affect Disord. 2011;135(1-3):148-53.

36. Buysse DJ, Reynolds CF 3rd, Monk TH, Berman SR, Kupfer DJ. The Pittsburgh sleep quality index: a new instrument for psychiatric practice and research. Psychiatry Res. 1989;28(2):193-213.

37. Allen JP, Litten RZ, Fertig JB, Babor T. A review of research on the alcohol use disorders identification test (AUDIT). Alcohol Clin Exp Res. 1997;21(4):613-9.

38. Hildebrand M. The psychometric properties of the drug use disorders identification test (DUDIT): a review of recent research. J Subst Abus Treat. 2015;53:52-9.

39. Alsabbagh ME, Eisa N, Alraiyes AH, Alraies MC, Chronic h C. Therapy: a rare complication revisited. BMJ Case Rep. 2013;2013

40. Cozzolongo R, Betterle C, Fabris P, Paola Albergoni M, Lanzilotta E, Manghisi OG. Onset of type 1 diabetes mellitus during peginterferon alpha-2b plus ribavirin treatment for chronic hepatitis C. Eur J Gastroenterol Hepatol. 2006; 18(6):689-92.

41. Eibl N, Gschwantler M, Ferenci P, Eibl MM, Weiss W, Schernthaner G. Development of insulin-dependent diabetes mellitus in a patient with chronic hepatitis C during therapy with interferon-alpha. Eur J Gastroenterol Hepatol. 2001;13(3):295-8.

42. Younossi ZM, Stepanova M, Zeuzem S, Dusheiko G, Esteban R, Hezode $C$, et al. Patient-reported outcomes assessment in chronic hepatitis C treated with sofosbuvir and ribavirin: the VALENCE study. J Hepatol. 2014;61(2):228-34.

43. Cacoub P, Ratziu V, Myers RP, Ghillani P, Piette JC, Moussalli J, Poynard T, Multivirc $G$. Impact of treatment on extra hepatic manifestations in patients with chronic hepatitis C. J Hepatol. 2002;36(6):812-8. 
44. Kraus MR, Schafer A, Teuber G, Porst H, Sprinzl K, Wollschlager S, Keicher C, Scheurlen M. Improvement of neurocognitive function in responders to an antiviral therapy for chronic hepatitis C. Hepatology. 2013;58(2):497-504.

45. Zampino R, Boemio A, Sagnelli C, Alessio L, Adinolfi LE, Sagnelli E, Coppola N. Hepatitis B virus burden in developing countries. World I Gastroenterol. 2015;21(42):11941-53.

46. Kuhn T, Sayegh P, Jones JD, Smith J, Sarma MK, Ragin A, et al. Improvements in brain and behavior following eradication of hepatitis $C$. J Neuro-Oncol. 2017;23(4):593-602.

47. Byrnes V, Miller A, Lowry D, Hill E, Weinstein C, Alsop D, Lenkinski R, Afdhal $\mathrm{NH}$. Effects of anti-viral therapy and HCV clearance on cerebral metabolism and cognition. J Hepatol. 2012;56(3):549-56.

48. Negro F, Forton D, Craxi A, Sulkowski MS, Feld JJ, Manns MP. Extrahepatic morbidity and mortality of chronic hepatitis C. Gastroenterology. 2015 149(6):1345-60.

49. Midgard H, Weir A, Palmateer N, Lo Re V 3rd, Pineda JA, Macias J, Dalgard $\mathrm{O}$. HCV epidemiology in high-risk groups and the risk of reinfection. J Hepatol. 2016;65(1 Suppl):S33-45.

50. Islam N, Krajden M, Shoveller J, Gustafson P, Gilbert M, Buxton JA, et al. Incidence, risk factors, and prevention of hepatitis $C$ reinfection: a population-based cohort study. Lancet Gastroenterol Hepatol. 2017:2(3):200-10.

51. Midgard H, Bjoro B, Maeland A, Konopski Z, Kileng H, Damas JK, et al. Hepatitis C reinfection after sustained virological response. J Hepatol. 2016;64(5):1020-6.

Ready to submit your research? Choose BMC and benefit from:

- fast, convenient online submission

- thorough peer review by experienced researchers in your field

- rapid publication on acceptance

- support for research data, including large and complex data types

- gold Open Access which fosters wider collaboration and increased citations

- maximum visibility for your research: over $100 \mathrm{M}$ website views per year

At BMC, research is always in progress.

Learn more biomedcentral.com/submissions 